\title{
Efficacy, safety, Low density lipoprotein cholesterol lowering, and calculated 10- year cardiovascular risk reduction of alirocumab and evolocumab in addition to maximal tolerated cholesterol lowering therapy: a post-commercialization study
}

Parth Shah ${ }^{1 *}$, Charles J. Glueck', Naila Goldenberg' ${ }^{1}$ Sarah Min², Chris Mahida², llana Schlam², Matan Rothschild², Ali Huda ${ }^{2}$ and Ping Wang ${ }^{1}$

\begin{abstract}
Background: Efficacy and safety of proprotein convertase subtilisin-kexin type 9 (PCSK9) inhibitors, alirocumab (ALI) and evolocumab (EVO) have previously been evaluated through controlled clinical trials with selective patient groups. Post-commercially, in patients with heterozygous familial hypercholesterolemia $(\mathrm{HeFH})$ and/or cardiovascular disease (CVD) with suboptimal LDL cholesterol (LDLC) lowering on maximal tolerated cholesterol lowering therapy, we assessed efficacy and safety of ALI and EVO.

Methods: Post-commercially, we started 25 patients on ALI 75 mg, 15 on ALI 150 mg, and 32 on EVO 140 mg bi-weekly added to entry LDLC lowering regimen, with follow-up for a median 24 weeks. History, physical exam, demographics, and adverse event data were collected. Changes in LDLC and AHA and NIH calculated 10-year CVD risks were assessed on ALI and EVO.
\end{abstract}

Results: Of 72 patients, 25 had HeFH only, 25 CVD only, 22 had both, median age was 65 years, 63\% females, 38\% males, 86\% Caucasian, 11\% African-Americans, 17\% diabetics, 63\% on anti-hypertensives, and 7\% smokers. At entry, 30 (42\%) were on a statin and 42 (58\%) could not tolerate any statins.

At 24-weeks, median LDLC decreased on ALI 75 mg from 117 to 62 mg/dL (-54\%), on ALI 150 mg from 175 to 57 mg/dL (-63\%), and on EVO $140 \mathrm{mg}$ from 165 to $69 \mathrm{mg} / \mathrm{dL}(-63 \%), p<0.0001$ for all. Absolute and percent LDLC reduction did not differ $(p>$.05) between ALI 150 and EVO 140 mg, but were less on ALI 75 mg vs ALI 150 mg and EVO $140 \mathrm{mg}(p<.05)$.

Percent reductions in 10-year CVD risks by AHA and $\mathrm{NIH}$ calculators, respectively were ALI $75 \mathrm{mg}-22$ and $-44 \%$, ALI $150 \mathrm{mg}-31$ and $-50 \%$, and EVO $140 \mathrm{mg}-29$ and $-56 \%, p \leq .002$ for all.

The three most common adverse events included flu-like myositis 10\%, respiratory tract symptoms $8 \%$, and injection site reaction $6 \%$.

(Continued on next page)

\footnotetext{
* Correspondence: prshah06@gmail.com

${ }^{1}$ Graduate Medical Education Department, Jewish Hospital of Cincinnati,

Cincinnati, Ohio, USA

Full list of author information is available at the end of the article
} 
(Continued from previous page)

Conclusion: In patients with HeFH and/or CVD, LDLC was lowered by 63\% on EVO and ALI 150 mg, and 54\% on ALI $75 \mathrm{mg}$. Adverse events were minimal and tolerable. ALI and EVO represent paradigm shifts in LDLC lowering. Long term, post-commercial safety and efficacy remain to be determined.

Keywords: PCSK9 Inhibitor, Efficacy, Safety, Cardiovascular risk, Alirocumab, Evolocumab, Hypercholesterolemia, Lowdensity lipoprotein

\section{Background}

With coronary artery disease and stroke being the number one cause of mortality in the United States [1], there is undeniable evidence that high LDL cholesterol (LDLC) contributes to an increased risk of cardiovascular disease (CVD). According to the $\mathrm{CDC}$, approximately 78 million Americans ( $>21$ years age) are eligible for cholesterol lowering medication, but only $55 \%$ are taking such therapy, of whom about $90 \%$ are on a statin [2]. Proprotein convertase subtilisin/kexin type 9 (PCSK9) inhibitors such as alirocumab (ALI) and evolocumab (EVO) have transformed LDLC lowering [3]. PCKS9 inhibitors are indicated in patients with heterozygous familial hypercholesterolemia (HeFH), Simon Broom's Criteria [4] and/or WHO Dutch Lipid Criteria [5], and/ or in patients with cardiovascular disease (CVD) whose LDLC lowering is suboptimal despite maximal tolerated cholesterol lowering therapy.

Previously, we have projected that an estimated 24 million Americans could be eligible for PCSK9 inhibitor therapy $[6,7]$. Prior to commercialization, efficacy and safety of ALI and EVO in patients has been evaluated through randomized controlled clinical trials [8-12], which have stringent inclusion and exclusion criteria, creating a highly selective cohorts of study patients.

ALI ODYSSEY Phase III studies demonstrated that the mean percentage change in calculated low-density lipoprotein cholesterol (LDLC) from baseline to week 24 beyond statin effect was $-61 \%$ versus $0.8 \%$ (placebo), $p<0.001$ $[9,13]$. In 2,461 patients treated with ALI $150 \mathrm{mg}, 796$ (32\%) had two consecutive LDLC levels $<25 \mathrm{mg} / \mathrm{dl}$ while 288 (12\%) had two consecutive LDLC levels $<15 \mathrm{mg} / \mathrm{dl}$ [10]. In ODDYSSEY COMBO I, in addition to concurrent LDLC lowering therapy, ALI $75 \mathrm{mg}$ produced a $45.6 \%$ LDLC decrease from baseline at 24 weeks [3]. Furthermore, in the OSLER-1 and OSLER-2 phase III trials, EVO $140 \mathrm{mg}$ reduced LDLC by $-61 \%$ at the median 12 -week treatment mark, beyond statin effect. In a pool of 2,651 patients receiving EVO $140 \mathrm{mg}, 1609$ (61\%) had at least one LDLC $<25 \mathrm{mg} / \mathrm{dl}$ [11].

Compared to placebo in double-blind studies, there were minimal adverse reactions to the PCSK9 inhibitors with the difference being consistently $<2 \%[9,11]$.

Preliminary results of safety-efficacy controlled clinical trials, although not powered or designed to definitively assess CVD events, have revealed approximately 50\% CVD risk reduction $[9,11]$.

Statin intolerance, predominantly characterized by myalgia, myositis, and myopathy, occurs in 10-29\% of statin-treated patients $[14,15]$. PCSK9 inhibitor therapy could substantially benefit these patients [6]. In the GAUSS-3 study of patients with previous statin intolerance, $43 \%$ of patients on atorvastatin had muscular symptoms. When these patients were enrolled in Phase $B$, which compared ezetimibe and placebo versus EVO and placebo, $29 \%$ experienced myalgias on ezetimibe versus $21 \%$ of those on EVO [8]. Furthermore, LDLC reduction from baseline on ezetimibe was $-17 \%$ versus $-53 \%$ on EVO at 24 weeks. In patients with statin intolerance, EVO was effective and well-tolerated [8].

Before 2013 [16], an LDLC target of $<70 \mathrm{mg} / \mathrm{dl}$ was considered to be optimal for patients at high risk of coronary heart disease, and/or for type II diabetics. In treated patients from NHANES data, only $28 \%$ achieved LDLC < $70 \mathrm{mg} / \mathrm{dl}$ [17]. In 2014, the ACC/AHA guidelines [18] were no longer focused on LDLC targets $<70 \mathrm{mg} / \mathrm{dl}$, but suggested that high dose statins be given to patients matched to their calculated 10-year CVD event risk. It was suggested that LDLC be reduced by at least $50 \%$ in high risk patients, and by $30-49 \%$ in primary prevention of high risk patients [18]. In 2016, ACC Expert Consensus Decision Pathway re-introduced treatment thresholds, including LDLC $<70 \mathrm{mg} / \mathrm{dl}$ in high risk patients with CVD [19]. For patients with clinically stable atherosclerotic cardiovascular disease (ASCVD), LDLC was targeted to $<100 \mathrm{mg} / \mathrm{dl}$ and for those with CVD and comorbidities, LDLC targeted to $<70 \mathrm{mg} / \mathrm{dl}$ [19].

Our specific aim, in a post-commercialization, open label, real world environment, was to assess the safety and efficacy of ALI and EVO in lowering LDLC, and subsequent change in calculated 10-year CVD risk in patients with $\mathrm{HeFH}$ and/or CVD referred to a regional cholesterol center for diagnosis and treatment of hypercholesterolemia.

\section{Methods}

The procedures were in accordance with the ethical standards of human experimentation, and approved by The Jewish Hospital Institutional Review Board (JH\#12-03, 15-06). Informed consent was provided and signed prior to initiation of the study. 
Since the commercialization of PCSK9 inhibitors in July 2015, at our regional cholesterol center, 72 patients were started on either EVO or ALI based on qualifications for $\mathrm{HeFH}$ (HeFH, Simon Broom's Criteria [4], WHO Dutch Lipid Criteria score $>8$ [5]) and/or CVD with suboptimal LDLC lowering despite maximal tolerated cholesterol lowering therapy, including statin doses down to zero. $\mathrm{HeFH}$ was assessed by the presence of tendon xanthomas and LDLC $\geq 190 \mathrm{mg} / \mathrm{dl}$ and/or personal or family history of premature cardiovascular disease and/or history of severe hypercholesterolemia. CVD was defined as carotid artery disease, history of stroke/TIA, coronary artery disease, congestive heart failure associated with CVD, and peripheral vascular disease.

Prior to initiation of therapy, all patients were counseled on a low cholesterol and saturated fat diet, and received follow-up counseling at serial visits. Instructions on how to use PCSK9 inhibitor auto-injector pens, education on its mechanism of action, side effects, and actions to be taken for missed doses were provided. Emergency contact information was given.

ALI and EVO were given in addition to patients' entry maximal tolerated cholesterol lowering regimens. Insurance formulary coverage was taken into consideration when deciding whether to use ALI or EVO. If entry LDLC was $\leq 130 \mathrm{mg} / \mathrm{dl}$, ALI $75 \mathrm{mg} / \mathrm{ml}$ was used, while for LDLC $>130 \mathrm{mg} / \mathrm{dl}$, ALI $150 \mathrm{mg}$ was used, while EVO $140 \mathrm{mg}$ was used for any entry LDLC. Sub-cutaneous auto-injector pens were used every two weeks.

All patients were followed for a median of 24 weeks, $25^{\text {th }}-75^{\text {th }}$ percentile $24-28$ weeks. We obtained a detailed history (especially cardiovascular history, documented $\mathrm{HeFH}$ and history of statin intolerance), physical examination, and lab draws at baseline and after starting therapy at 4,12 , and 24 weeks. Patient characteristics obtained included: age, gender, weight, body mass index, systolic and diastolic blood pressures, history of diabetes, smoking, and treatment with anti-hypertensive medications. Adverse events after the initiation of the therapy were recorded and appropriate changes were made as needed. The changes in 10-year cardiovascular risk were assessed using ACC/AHA [18] and NIH Framingham [20] risk calculators.

Statistical software SAS version 9.4 and Prism were used for data analysis and presentation. Paired Wilcoxon analysis was used to compare entry and follow-up data. General linear models were used to assess differences in LDLC lowering for the two ALI doses and EVO after adjusting for treatment duration, age, race, gender, BMI, presence or absence of statin intolerance, HeFH $(+/-)$, and CVD (+/-). General linear models were also used to compare absolute and percent changes in LDLC in patients with and without entry statin intolerance, after adjusting for PCSK9 treatment type, treatment duration, age, race, gender, $\mathrm{BMI}, \mathrm{HeFH}(+/-)$, CVD $(+/-)$, and entry LDLC.

Absolute changes in LDLC were also assessed in a mixed effect model for repeated measures.

\section{Results}

Table 1 displays entry characteristics of our cohort of 72 patients. Median age at entry was 65 years, 86\% Caucasian, $11 \%$ African-American, $1 \%$ Asian, $1 \%$ Indian. Of the 72 patients, $63 \%$ were female, $38 \%$ male, $17 \%$ had diabetes, $7 \%$ smoked, and $63 \%$ were on anti-hypertensive medication. Of the 72 patients, 25 (35\%) had HeFH only, 25 (35\%) had CVD only, and 22 (31\%) had both HeFH and CVD (Table 1). Of the 72 patients, 42 (58\%) could not tolerate any dose of statin (Table 1). Before starting PCSK9 inhibitor therapy, 16 patients were taking a statin only, 5 statin and ezetimibe, 2 statin and colesevelam, 7 statin, ezetimibe, and colesevelam, and 11 ezetimibe and/or colesevelam (Table 1).

Tables 2,3 , and 4 display $25^{\text {th }}, 50^{\text {th }}$, and $75^{\text {th }}$ percentiles for LDLC and total cholesterol, triglyceride, and HDL cholesterol categorized by drug group and further characterized by $\mathrm{HeFH}$ and CVD, Table 3. On ALI $75 \mathrm{mg}$, entry LDLC fell from a median of $117-62 \mathrm{mg} / \mathrm{dl}$, a 54\% decrement, Table 2. On ALI $150 \mathrm{mg}$, entry LDLC fell from a median of $175-57 \mathrm{mg} / \mathrm{dl}$, a $63 \%$ reduction, and on EVO $140 \mathrm{mg}$, entry LDLC fell from 165 to $69 \mathrm{mg} / \mathrm{dl}$, a $63 \%$ reduction, Table 2, Fig. 1 . Median, $25^{\text {th }}$ and $75^{\text {th }}$ percentiles for follow-up were 24,24 , and 28 weeks, Table 1 .

Figures $1,2,3$ display $25^{\text {th }}, 50^{\text {th }}$, and $75^{\text {th }}$ percentiles of LDLC levels at study entry and 4, 12, and 24 weeks followup in the ALI $75 \mathrm{mg}$, ALI $150 \mathrm{mg}$, and EVO $140 \mathrm{mg}$ groups. Median LDLC in the ALI $75 \mathrm{mg}$ group decreased from 117 to $68 \mathrm{mg} / \mathrm{dl}$ at 4 weeks, $61 \mathrm{mg} / \mathrm{dl}$ at 12 weeks, and $62 \mathrm{mg} / \mathrm{dl}$ at 24 weeks $(p<.0001$ for all). Median LDLC in the ALI $150 \mathrm{mg}$ group decreased from 175 to $66 \mathrm{mg} / \mathrm{dl}$ at 4 weeks, $68 \mathrm{mg} / \mathrm{dl}$ at 12 weeks and $57 \mathrm{mg} / \mathrm{dl}$ at 24 weeks $(p<.0001$ overall, Fig. 2). Median LDLC in the EVO $140 \mathrm{mg}$ group decreased from 165 to $83 \mathrm{mg} / \mathrm{dl}$ at 4 weeks, $75 \mathrm{mg} / \mathrm{dl}$ at 12 weeks, and $69 \mathrm{mg} / \mathrm{dl}$ at 24 weeks $(p<.0001$ for all, Fig. 3). For each drug group, there was a sharp reduction in LDLC by 4 weeks, which remained stable at 12 and 24 weeks (Figs. 1, 2, 3).

In the mixed effect model for repeated measures, LDLC reductions on ALI 75, ALI 150, and EVO $140 \mathrm{mg}$ were significant, $p<.0001$ for all.

Table 3 demonstrates the number of patients who had attained at least one measurement of LDLC $<70 \mathrm{mg} / \mathrm{dl}$ while on ALI $75 \mathrm{mg}$, ALI $150 \mathrm{mg}$, or EVO $140 \mathrm{mg}$. For the total cohort, median entry LDLC was $149 \mathrm{mg} / \mathrm{dl}$, $177 \mathrm{mg} / \mathrm{dl}$ for HeFH only, $131 \mathrm{mg} / \mathrm{dl}$ for CVD only, and $169 \mathrm{mg} / \mathrm{dl}$ for both $\mathrm{HeFH}$ and CVD, Table 3. Of the 25 patients in the $\mathrm{HeFH}$ only group, 12 (48\%) achieved 
Table 172 patients at study entry before treatment with Alirocumab or Evolocumab

\begin{tabular}{|c|c|}
\hline Age at entry (years) Mean $\pm S D,\left[25^{\text {th }}, 50^{\text {th }}, 75^{\text {th }}\right.$ percentiles $]$ & $64.1 \pm 9.6,[58,65,72]$ \\
\hline BMI $\left(\mathrm{kg} / \mathrm{m}^{2}\right)$ Mean $\pm S D,\left[25^{\text {th }}, 50^{\text {th }}, 75^{\text {th }}\right.$ percentiles $]$ & $29.3 \pm 5.1,[25.3,29.0,32.2]$ \\
\hline Race & 62 White (86\%), 8 Black (11\%), 1 Asian (1\%), 1 Indian (1\%) \\
\hline Gender & $45 \mathrm{~F}(63 \%), 27 \mathrm{M}(38 \%)$ \\
\hline Diabetes & 12 Yes (17\%), 60 No (83\%) \\
\hline Smoke & 5 Yes (7\%), 67 No (93\%) \\
\hline BP lowering drug & 45 Yes (63\%), 27 No (38\%) \\
\hline $\mathrm{HeFH}$ & 47 Yes (65\%), 25 No (35\%); 25 had HeFH \& no CVD (35\%) \\
\hline CVD & 47 Yes (65\%), $25 \mathrm{No}(35 \%) ; 25$ had CVD \& no HeFH (35\%) \\
\hline Both HeFH \& CVD & $22(31 \%)$ \\
\hline Statin intolerant & 42 Yes (58\%), 30 No (42\%) \\
\hline Medication use at entry & Statin only, $N=16$ \\
\hline \multirow[t]{3}{*}{ Taking Statin $(n=30)$} & Statin + ezetimibe, $N=5$ \\
\hline & Statin + colesevelam, $N=2$ \\
\hline & Statin + ezetimibe + colesevelam, $N=7$ \\
\hline \multirow[t]{4}{*}{ Not taking statin $(n=42)$} & Ezetimibe only, $N=4$ \\
\hline & Colesevelam only, $N=2$ \\
\hline & Ezetimibe + colesevelam, $N=5$ \\
\hline & Nothing, $N=31$ \\
\hline Follow up weeks on ALI or EVO Mean \pm SD, $\left[25^{\text {th }}, 50^{\text {th }}, 75^{\text {th }}\right.$ percentiles $]$ & $26 \pm 5,[24,28]$ \\
\hline
\end{tabular}

Table 2 Changes in LDLC and CVD risk from study entry to last follow up in 72 patients taking Alirocumab or Evolocumab

\begin{tabular}{|c|c|c|c|c|c|c|c|c|c|c|}
\hline \multirow{3}{*}{ Variable measured } & & \multirow{2}{*}{\multicolumn{3}{|c|}{$\begin{array}{l}\text { Alirocumab } 75 \mathrm{mg} \\
(n=25) \text { Follow up } \\
\text { length median } 24 \text { weeks } \\
\text { percentile }\end{array}$}} & \multirow{2}{*}{\multicolumn{3}{|c|}{$\begin{array}{l}\text { Alirocumab } 150 \mathrm{mg} \\
(n=15) \text { Follow up } \\
\text { length median } 26 \text { weeks } \\
\text { percentile }\end{array}$}} & \multirow{2}{*}{\multicolumn{3}{|c|}{$\begin{array}{l}\text { Evolocumab } 140 \mathrm{mg} \\
(n=32) \text { Follow up } \\
\text { length median } 24 \text { weeks } \\
\text { percentile }\end{array}$}} \\
\hline & & & & & & & & & & \\
\hline & & $25^{\text {th }}$ & $50^{\text {th }}$ & $75^{\text {th }}$ & $25^{\text {th }}$ & $50^{\text {th }}$ & $75^{\text {th }}$ & $25^{\text {th }}$ & $50^{\text {th }}$ & $75^{\text {th }}$ \\
\hline \multirow[t]{6}{*}{ LDLC } & Entry (mg/dl) & 100 & 117 & 143 & 133 & 175 & 214 & 143 & 165 & 211 \\
\hline & Follow up (mg/dl) & 47 & 62 & 84 & 49 & 57 & 86 & 46 & 69 & 109 \\
\hline & $\begin{array}{l}\text { Absolute change (mg/ } \\
\text { dl) }\end{array}$ & -35 & -67 & -85 & -89 & -104 & -141 & -65 & -89 & -131 \\
\hline & P (paired Wilcoxon) & \multicolumn{3}{|c|}{$p<.0001$} & \multicolumn{3}{|c|}{$p<.0001$} & \multicolumn{3}{|c|}{$p<.0001$} \\
\hline & Percent change (\%) & -27 & -54 & -63 & -56 & -63 & -72 & -40 & -63 & -71 \\
\hline & P (Wilcoxon) & \multicolumn{3}{|c|}{$p<.0001$} & \multicolumn{3}{|c|}{$p<.0001$} & \multicolumn{3}{|c|}{$p<.0001$} \\
\hline \multirow{6}{*}{$\begin{array}{l}\text { CVD risk for next } 10 \text { years With } \mathrm{AHA} \\
\text { calculator }\end{array}$} & Entry (\%) & 3.9 & 6.2 & 18.0 & 5.4 & 9.3 & 20.4 & 4.3 & 11.5 & 18.6 \\
\hline & Follow up (\%) & 3.3 & 6.2 & 10.1 & 2.3 & 7.0 & 15.1 & 2.9 & 6.7 & 20.2 \\
\hline & Absolute change & -0.2 & -1.6 & -5.4 & -0.7 & -3.3 & -6.0 & -0.6 & -2.4 & -5.7 \\
\hline & P (paired Wilcoxon) & \multicolumn{3}{|c|}{$p=.0001$} & \multicolumn{3}{|c|}{$p=.0043$} & \multicolumn{3}{|c|}{$p=<.0001$} \\
\hline & Percent change & -1.9 & -22.2 & -40.7 & -22.2 & -31.3 & -39.0 & -9.1 & -28.7 & -52.3 \\
\hline & P (Wilcoxon) & \multicolumn{3}{|c|}{$p=.0002$} & \multicolumn{3}{|c|}{$p=.0015$} & \multicolumn{3}{|c|}{$p<.0001$} \\
\hline \multirow{6}{*}{$\begin{array}{l}\text { CVD risk for next } 10 \text { years With } \mathrm{NIH} \\
\text { calculator }\end{array}$} & Entry (\%) & 6.8 & 11.2 & 19.8 & 10.6 & 17.2 & 25.7 & 9.6 & 17.4 & 26.4 \\
\hline & Follow up (\%) & 4.3 & 7.4 & 11.7 & 5.1 & 6.5 & 12.3 & 5.3 & 8.0 & 12.0 \\
\hline & Absolute change & -1.4 & -4.2 & -10.5 & -4.4 & -9.1 & -16.2 & -3.0 & -7.1 & -14.7 \\
\hline & P (paired Wilcoxon) & \multicolumn{3}{|c|}{$p<.0001$} & \multicolumn{3}{|c|}{$p=.0001$} & \multicolumn{3}{|c|}{$P<.0001$} \\
\hline & Percent change & -21.4 & -43.7 & -53.5 & -41.6 & -49.8 & -61.4 & -27.9 & -55.5 & -66.2 \\
\hline & P (Wilcoxon) & \multicolumn{3}{|c|}{$p<.0001$} & \multicolumn{3}{|c|}{$p=.0001$} & \multicolumn{3}{|c|}{$p<.0001$} \\
\hline
\end{tabular}


Table 3 Number (\%) of patients who had at least one measure of LDLC $<70$ mg/dl on Alirocumab or Evolocumab for 24 weeks

\begin{tabular}{lllll}
\hline & HeFH only $(n=25)$ Entry & CVD only $(n=25)$ & HeFH \& CVD $(n=22)$ & Total cohort $(n=72)$ \\
& LDLC 25 $, 50^{\text {th }}, 75^{5 \text { th }} \%$ tile: & {$[104,131,148 \mathrm{mg} / \mathrm{dl}]$} & {$[122,169,214 \mathrm{mg} / \mathrm{dl}]$} & {$[123,149,193 \mathrm{mg} / \mathrm{dl}]$} \\
& {$[149,177,220 \mathrm{mg} / \mathrm{dl}]$} & & & $19 / 25(76 \%)$ \\
\hline Alirocumab $75 \mathrm{mg} / 2$ weeks $(n=25)$ & $2 / 5(40 \%)$ & $12 / 14(86 \%)$ & $5 / 6(83 \%)$ & $11 / 15(73 \%)$ \\
Alirocumab $150 \mathrm{mg} / 2$ weeks $(n=15)$ & $2 / 4(50 \%)$ & $3 / 3(100 \%)$ & $6 / 8(75 \%)$ & $18 / 32(56 \%)$ \\
Evolocumab $140 \mathrm{mg} / 2$ weeks $(n=32)$ & $8 / 16(50 \%)$ & $7 / 8(88 \%)$ & $3 / 8(38 \%)$ & $48 / 72(67 \%)$ \\
All 3 treatment groups $(n=72)$ & $12 / 25(48 \%)$ & $22 / 25(88 \%)$ & $14 / 22(64 \%)$ & \\
\hline
\end{tabular}

LDLC $<70 \mathrm{mg} / \mathrm{dl}$, Table 3 . Of the 25 patients with CVD only, $22(88 \%)$ achieved LDLC $<70 \mathrm{mg} / \mathrm{dl}$. Of the 22 patients with both $\mathrm{HeFH}$ and CVD, 14 (64\%) achieved LDLC <70 mg/dl, Table 3.

As displayed in Table 3, of the 25 patients on ALI $75 \mathrm{mg}, 19$ (76\%) achieved LDLC $<70 \mathrm{mg} / \mathrm{dl}$. Of the 15 patients on ALI $150 \mathrm{mg}, 11$ (73\%) achieved LDLC $<70 \mathrm{mg} / \mathrm{dl}$. Of 32 patients on EVO $140 \mathrm{mg}, 18$ (56\%) achieved LDLC $<70 \mathrm{mg} / \mathrm{dL}$. In the total cohort of 72 patients, 48 (67\%) achieved LDLC <70 mg/dl, Table 3.

As shown in Table 4, reductions in LDLC were accompanied by median reduction in total cholesterol of $32 \%$ (ALI $75 \mathrm{mg}$ ), 48\% (ALI $150 \mathrm{mg}$ ), and 39\% (EVO $140 \mathrm{mg}$ ), $p<.0001$ for all. On ALI $75 \mathrm{mg}$, ALI $150 \mathrm{mg}$, and EVO
$140 \mathrm{mg}$, there were also significant median reductions in triglycerides (TG) of $21 \%, 32 \%$, and $23 \%$ ( $p=.01, p=.002$, $p=.009)$, respectively (Table 4). Median HDLC increased $5 \%$ on ALI $75 \mathrm{mg}, 11 \%$ on ALI $150 \mathrm{mg}$ and $8 \%$ on EVO $140 \mathrm{mg}(p=.092, p=.010, p=.003$, Table 4$)$.

By stepwise regression, among age, race, BMI, gender, statin intolerance (+/-), HeFH (+/-), CVD (+/-), PCSK9 treatment type, and follow-up duration, the only significant explanatory variable for absolute change or percent change in LDLC was PCSK9 treatment type. Using a general linear model, adjusting for age, race, BMI, gender, statin intolerance $(+/-), \mathrm{HeFH}(+/-), \mathrm{CVD}(+/-)$ and follow-up duration, absolute and percent LDLC reduction were greater with ALI $150 \mathrm{mg}$ than with ALI

Table 4 Change in total cholesterol, triglyceride, and HDL cholesterol in 72 patients treated with Alirocumab or Evolocumab

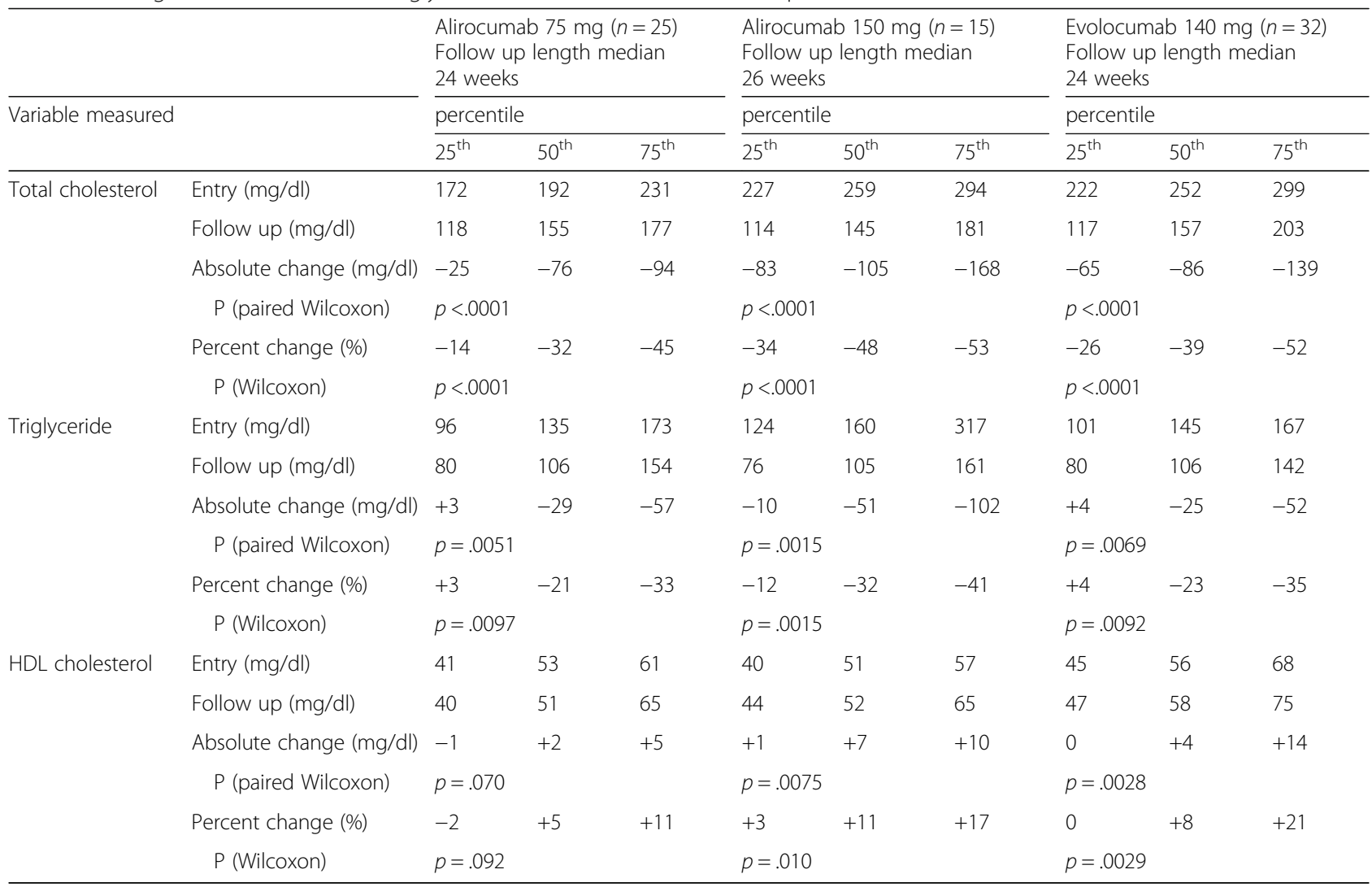




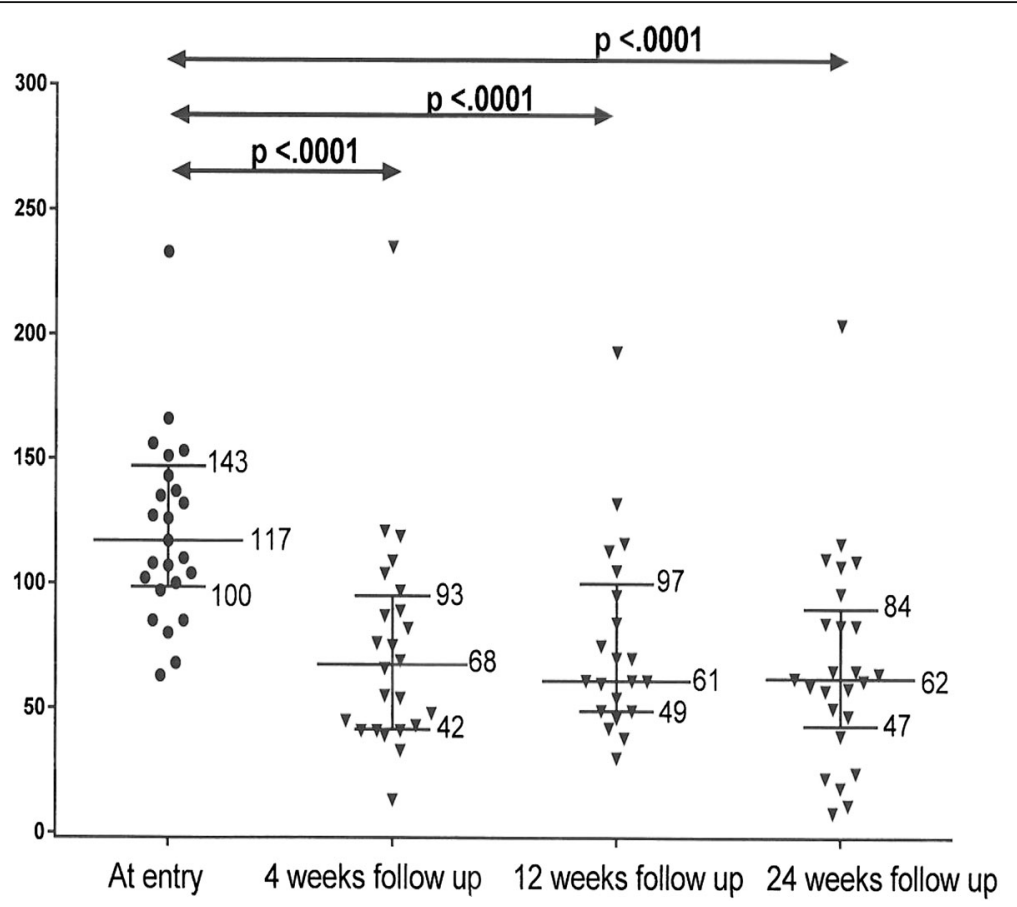

Fig. 1 Median and $25^{\text {th }}$ and $75^{\text {th }}$ percentile LDLC (mg/dl) at study entry and 4, 12, and 24 weeks follow-up on Alirocumab 75 mg every two weeks

$75 \mathrm{mg}(p=.004, p=.011)$, and greater with EVO $140 \mathrm{mg}$ than with ALI $75 \mathrm{mg}(p=.014, p=.044)$, Table 5. ALI $150 \mathrm{mg}$ and EVO $140 \mathrm{mg}$ did not differ in regards to LDLC reduction $(p>0.05)$. In a second general linear model, covariance adjusted absolute and \% reduction in LDLC on therapy was greater in the 30 statin-tolerant patients who continued statins plus ALI or EVO for
24 weeks, versus the 42 patients with statin intolerance, $p=.0008, p=.013$, Table 5 .

Reductions in LDLC were accompanied by significant absolute and percent reductions in estimated 10-year CVD risk as determined by both the ACC/AHA and the $\mathrm{NIH}$ calculators (Table 2). On ALI $75 \mathrm{mg}$, ALI $150 \mathrm{mg}$, and EVO $140 \mathrm{mg}$, by the NIH calculator, at last follow-

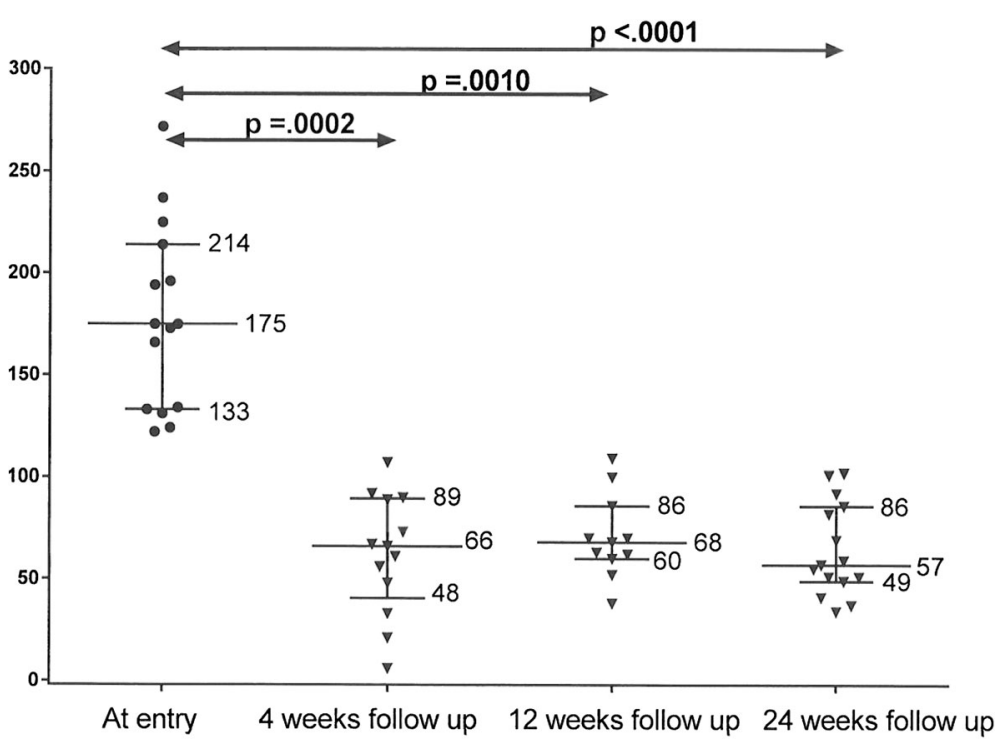

Fig. 2 Median and $25^{\text {th }}$ and $75^{\text {th }}$ percentile LDLC (mg/dl) at study entry and 4, 12, and 24 weeks follow-up on Alirocumab 150 mg every two weeks 


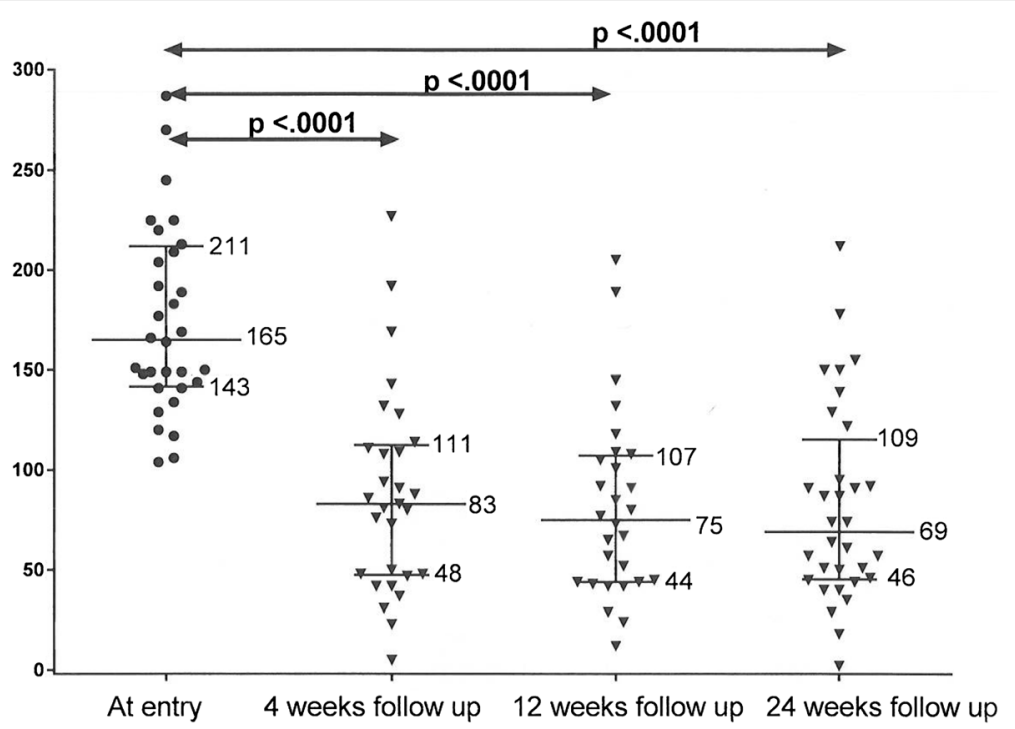

Fig. 3 Median and $25^{\text {th }}$ and $75^{\text {th }}$ percentile LDLC (mg/dl) at study entry and 4, 12, and 24 weeks follow-up on Evolocumab 140 mg every two weeks

up, 10-year CVD risk was reduced by median of 44,50 and $56 \%, p \leq .0001$ for all. By the AHA calculator, at last follow-up, 10-year CVD risk was reduced by median of 22,31 and $29 \%, p<.002$ for all (Table 2).

Table 6 displays adverse events (AE) in the 72 patients on the 3 treatment regimens. The three most common adverse events were a flu-like myositis (10\%), respiratory tract symptoms/infection (8\%), and injection site reaction (6\%), Table 6. As displayed in Table 6, there were no significant differences among the 3 groups for AEs $(p>0.05)$.

As displayed in Table 7, the statin tolerant group, taking a statin plus ALI or EVO, had fewer AEs than the statin intolerant group, taking ALI or EVO only, $0=.039$.

One patient had coronary bypass revision due to scar tissue growth within one month of starting therapy and another patient had three stents placed within two months of starting therapy. In neither of the cardiovascular event patients was the PCSK9 inhibitor therapy stopped and we did not attribute these two events to the PCSK9 inhibitor therapy.

\section{Discussion}

After taking into account the rising CVD costs in the United States, projected by the AHA to be approximately $\$ 1$ trillion by 2030 , we have postulated that the cost to society with an estimated 50\% CVD risk reduction with PCSK9 inhibitor therapy $[6,10,11]$ would be in the middle of the range of societal costs for CVD [6]. Subsequently, in 103 hypercholesterolemic patients [7] (61 with previous CVD events, first CVD event at median age 55, median LDLC $139 \mathrm{mg} / \mathrm{dL}$ despite maximal tolerated cholesterol-lowering therapy), we estimated direct and indirect costs of CVD, cost of estimated next

Table 5 Comparisons of LDLC change among PCSK9 inhibitor treatment groups and between statin tolerant and intolerant groups

\begin{tabular}{|c|c|c|c|}
\hline & Alirocumab 75 mg $(n=25)$ & Alirocumab 150 mg ( $n=15)$ & Evolucumab $140 \mathrm{mg}(n=32)$ \\
\hline LS means \pm SE of change in LDLC (mg/dl) & $-59 \pm 10$ & $-110 \pm 14$ & $-95 \pm 9$ \\
\hline \multirow[t]{2}{*}{ Group differences } & ALI 75 vs ALI 150, $p=.004$ & & \\
\hline & ALI 75 vs EVO 140, $p=.014$ & & \\
\hline LS means \pm SE of $\%$ change in LDLC (\%) & $-42 \pm 5 \%$ & $-63 \pm 7 \%$ & $-56 \pm 4 \%$ \\
\hline \multirow[t]{2}{*}{ Group differences } & ALI 75 vs ALI 150, $p=.011$ & & \\
\hline & ALI 75 vs EVO 140, $p=.044$ & & \\
\hline LS means \pm SE of change in LDLC (mg/dl) & $-109 \pm 7$ & $-78 \pm 5$ & \\
\hline Group differences & $p=.0008$ & & \\
\hline LS means \pm SE of $\%$ change in LDLC (\%) & $-63 \pm 5 \%$ & $-48 \pm 4 \%$ & \\
\hline Group differences & $p=.013$ & & \\
\hline
\end{tabular}

LS means for 3 treatment groups, adjusted for treatment duration, age, BMI, race, gender, statin intolerance (yes-no), HeFH (yes-no), and CVD (yes-no)

LS means for statin tolerant vs intolerant groups, adjusted for PCSK9 groups, treatment duration, age, BMI, race, gender, HeFH (yes-no), CVD (yes-no) and LDLC at entry 
Table 6 Adverse events in 72 patients on Alirocumab 75 or 150 mg, or Evolocumab 140 mg, by treatment regimens

\begin{tabular}{|c|c|c|c|c|}
\hline & $\begin{array}{l}\text { All } 3 \text { treatment groups }(n=72) \\
\text { F45, M27 Follow up length } \\
\text { median } 25 \text { weeks }\end{array}$ & $\begin{array}{l}\text { Alirocumab } 75 \mathrm{mg}(n=25) \\
\text { F12, M13 Follow up length } \\
\text { median } 24 \text { weeks }\end{array}$ & $\begin{array}{l}\text { Alirocumab } 150 \mathrm{mg}(n=15) \\
\text { F10, M5 Follow up length } \\
\text { median } 26 \text { weeks }\end{array}$ & $\begin{array}{l}\text { Evolocumab } 140 \mathrm{mg}(n=32) \\
\text { F23, M9 Follow up length } \\
\text { median } 24 \text { weeks }\end{array}$ \\
\hline Flu-like myositis & $8(10 \%)$ & $1(4 \%)$ & $5(33 \%)$ & $2(6 \%)$ \\
\hline $\begin{array}{l}\text { Respiratory } \\
\text { tract infection/ } \\
\text { symptoms }\end{array}$ & $6(8 \%)$ & $1(4 \%)$ & $1(7 \%)$ & $4(13 \%)$ \\
\hline $\begin{array}{l}\text { Inject site } \\
\text { reaction }\end{array}$ & $4(6 \%)$ & $1(4 \%)$ & $1(7 \%)$ & $2(6 \%)$ \\
\hline Fatigue & $1(1 \%)$ & $1(4 \%)$ & & \\
\hline $\begin{array}{l}\text { Headache/ } \\
\text { mental acuity/ } \\
\text { mood }\end{array}$ & $2(3 \%)$ & & $1(7 \%)$ & $1(3 \%)$ \\
\hline $\begin{array}{l}\text { Urticaria/ } \\
\text { itchiness }\end{array}$ & $2(3 \%)$ & $1(4 \%)$ & & $1(3 \%)$ \\
\hline G.l. symptom & $2(3 \%)$ & & $1(7 \%)$ & $1(3 \%)$ \\
\hline Weight gain & $1(1 \%)$ & & & $1(3 \%)$ \\
\hline Hair loss & $1(1 \%)$ & & & $1(3 \%)$ \\
\hline $\begin{array}{l}\text { Any adverse } \\
\text { events }\end{array}$ & $22(31 \%)$ & $5(20 \%)$ & $7(47 \%)$ & $10(31 \%)$ \\
\hline $\begin{array}{l}\text { No adverse } \\
\text { events }\end{array}$ & $50(69 \%)$ & $20(80 \%)$ & $8(53 \%)$ & $22(69 \%)$ \\
\hline
\end{tabular}

Comparing adverse events (any vs none), no difference among 3 treatment groups (Fisher's $p>.05$ )

10-year CVD events, and PCSK9 inhibitor costs to assess whether PCSK9 inhibitors would provide an incremental cost-effectiveness ratio [21] within a society willingness to pay threshold [22]. We concluded [7] that the net cost of PCSK9 inhibitor therapy, assuming a 50\% reduction of CVD events on PCSK9 inhibitor therapy, was $\$ 7,000$ per patient per year in the past, and the net cost of therapy over the next 10 year period was estimated to be $\$ 12,459$ per patient per year, well below the $\$ 50,000$ per quality adjusted life year [22] gained which has been used to judge value of a pharmacologic therapy.

Despite maximal tolerated cholesterol lowering therapy, many patients fail to achieve optimal LDLC lowering [23-25], with only $28 \%$ of patients in NHANES achieving LDLC $<70 \mathrm{mg} / \mathrm{dl}$ on treatment [17]. Failure to reach optimal LDLC lowering is related to statin intolerance [26, 27], expense, lack of insurance coverage, or variations in statin availability across states in insurance, race, and ethnicity [23]. In the current study, 42 of 72

Table 7 Adverse events in 72 patients on Alirocumab or Evolocumab, by entry statin intolerance group

\begin{tabular}{|c|c|c|c|}
\hline & $\begin{array}{l}\text { All }(n=72) \text { F } 45, \text { M27 Follow up } \\
\text { length median } 25 \text { weeks }\end{array}$ & $\begin{array}{l}\text { Statin tolerant, taking statin }(n=30) \text { F15, M15 } \\
\text { Follow up length median } 24 \text { weeks }\end{array}$ & $\begin{array}{l}\text { Statin intolerant }(n=42) \text { F30, M12 Follow } \\
\text { up length median } 23 \text { weeks }\end{array}$ \\
\hline Flu-like myositis & $8(10 \%)$ & $1(3 \%)$ & $7(17 \%)$ \\
\hline $\begin{array}{l}\text { Respiratory tract } \\
\text { infection/symptoms }\end{array}$ & $6(8 \%)$ & $2(7 \%)$ & $4(9 \%)$ \\
\hline Inject site reaction & $4(6 \%)$ & $2(7 \%)$ & $2(5 \%)$ \\
\hline Fatigue & $1(1 \%)$ & & $1(2 \%)$ \\
\hline $\begin{array}{l}\text { Headache/mental } \\
\text { acuity/mood }\end{array}$ & $2(3 \%)$ & & $2(5 \%)$ \\
\hline Urticaria/itchiness & $2(3 \%)$ & & $2(5 \%)$ \\
\hline G.l. symptom & $2(3 \%)$ & & $2(5 \%)$ \\
\hline Weight gain & $1(1 \%)$ & & $1(2 \%)$ \\
\hline Hair loss & $1(1 \%)$ & & $1(2 \%)$ \\
\hline Any adverse events & $22(31 \%)$ & $5(17 \%)$ & $17(40 \%)$ \\
\hline No adverse events & $50(69 \%)$ & $25(83 \%)$ & $25(60 \%)$ \\
\hline
\end{tabular}

Comparing adverse events (any vs none), there were fewer adverse events in the statin tolerant group, taking statin + ALI or EVO than in the statin intolerant group taking ALI or EVO only (Fisher's $p=.039$ ) 
patients (58\%) were statin intolerant, a problem which affects at least $10-29 \%$ of patients taking statins [14, 15, 28]. Moreover $60 \%$ of patients who discontinue statins report statin intolerance as the reason [29]. However, congruent with our open label, post commercialization study, as demonstrated by the controlled clinical trial, GAUSS-3, in patients with statin intolerance, EVO was well-tolerated and effective [8]. PCSK9 inhibitors now offer the promise of optimizing LDLC in most patients with $\mathrm{HeFH}, \mathrm{CVD}$, and concurrent statin intolerance [9-12, 30-32].

ALI and EVO have been found to be very efficacious and safe during phase II and III randomized controlled trials with minimal adverse events compared to placebo $[8,9,11]$. In the phase II MENDEL study, without a concurrent lipid-lowering regimen, EVO $140 \mathrm{mg}$ showed a $51 \%$ reduction in LDLC at 12 weeks [33]. In SAR236553/REGN727 phase II trials with ALI $150 \mathrm{mg}$ added on a stable atorvastatin dose, there was $72 \%$ LDLC reduction at 12 weeks [34]. During phase III trials with patients on maximal tolerated cholesterol lowering therapy along with ALI $150 \mathrm{mg}$ and ALI $75 \mathrm{mg}$ every two weeks, there was a 61 and $46 \%$ reduction, respectively, from baseline in LDLC at median 24 weeks [3, 9]. In OSLER-1 and 2, patients on EVO $140 \mathrm{mg}$ every two weeks or $420 \mathrm{mg}$ once/month had LDLC reduction by $61 \%$ at median 12 weeks on top of antecedent cholesterol lowering therapy [11].

Based on FDA indications and third party insurance drug coverage, our current study was done in $\mathrm{HeFH}$ and CVD patients with suboptimal cholesterol lowering despite maximal tolerated cholesterol lowering therapy. This qualified all our cohort, with minimal exclusion criteria, for initiation of PCSK9 inhibitor therapy, a cohort much more diverse than those in the placebo-controlled randomized clinical trials $[9,11]$. Rallidis et al. have recently demonstrated that in patients who presented with myocardial infarction, $20 \%$ had definite/probable $\mathrm{HeFH}$ and 51\% had possible $\mathrm{HeFH}$ [35]. Over a 9-year followup period, $39 \%$ of 255 patients had a major adverse coronary event despite $84.3 \%$ being on statins, with only $2.3 \%$ achieving LDLC $<70 \mathrm{mg} / \mathrm{dl}$ [35]. Definite/probable $\mathrm{HeFH}$ was independently associated with major adverse coronary events [35]. Our current study cohort included 25 patients with $\mathrm{HeFH}$ only, 25 with CVD only, and 22 with both. Moreover, in our current study, 48/72 (67\%) patients obtained optimal LDLC reduction to $<70 \mathrm{mg} / \mathrm{dl}$ while taking ALI or EVO. Of the 25 patients with $\mathrm{HeFH}$ only, 12 (48\%) had $\geq 1 \mathrm{LDLC}<70 \mathrm{mg} / \mathrm{dl}$ on therapy, as did 22 of 25 (88\%) patients with CVD only, and 14 of 22 (64\%) with both $\mathrm{HeFH}$ and CVD. Our findings support the central importance of PCSK9 inhibitor therapy in high-risk patients with $\mathrm{HeFH}$ and/or CVD who otherwise do not achieve LDLC $<70 \mathrm{mg} / \mathrm{dl}$ with maximal tolerated LDLC lowering regimens.
In our current study, median absolute reductions in LDLC on ALI $75 \mathrm{mg}$, ALI $150 \mathrm{mg}$, and EVO $140 \mathrm{mg}$ were respectively 67,104 , and $89 \mathrm{mg} / \mathrm{dl}$, which, if maintained, should lead to sharp reductions in CVD events. In our current study, median LDLC reduction from baseline was $54 \%$ and $63 \%$ on ALI 75 and $150 \mathrm{mg}$, and $63 \%$ on EVO $140 \mathrm{mg}$ respectively at 24 weeks. Collins et al. reported that reduction of LDLC by $77 \mathrm{mg} / \mathrm{dl}$ for 5 years in 10,000 patients would prevent major vascular events in 1,000 (10\%), an absolute benefit in those who had pre-existing CVD, and in 500 patients ( $5 \%$ absolute benefit) in primary prevention [36]. In the 30 statin-tolerant patients in our current study, subsequently receiving both statins and ALI or EVO, absolute and percent LDLC reduction was greater than in the 42 patients with statin intolerance at entry who subsequently received only ALI or EVO. LDLC reduction in our real world setting for ALI $150 \mathrm{mg}$ and EVO $140 \mathrm{mg}$ was within 1-2\% of that reported in the placebo controlled trials while in the ALI 75 mg group it was about $9 \%$ higher than the previous trials $[9,11]$.

From past vascular studies on statins, regression of plaque can be induced when LDLC is held $\sim 70 \mathrm{mg} / \mathrm{dl}$ or below [37]. Patients receiving atorvastatin $80 \mathrm{mg}$ have been shown to have regression of carotid-artery intima-media within 12 months with an average achieved LDLC of $76 \mathrm{mg} / \mathrm{dl}$ [38]. The NIH post-CABG study showed that patients who were post CABG and selected for a lower target LDLC group $(90 \mathrm{mg} / \mathrm{dl}$ vs $135 \mathrm{mg} / \mathrm{dl})$ had no angiographic progression of coronary plaques. This suggested that lower target LDLC leads to a significant reduction in coronary events and mortality, inferring that further reduction of coronary plaque burden could lead to further reduced coronary event rates and mortality [39]. When patients were given rosuvastatin $40 \mathrm{mg}$ in the ASTEROID trial, mean LDLC was reduced from $130 \mathrm{mg} / \mathrm{dl}$ to $60 \mathrm{mg} / \mathrm{dl}$ (53\%) with a total atheroma volume reduction median of $6.8 \%$ as well as a significant reduction in all intravenous ultrasound measurements of atheroma burden [40]. Consequently, in the recent GLAGOV study [41], compared with statinplacebo, the EVO-statin group achieved lower mean LDLC (93.0 vs $36.6 \mathrm{mg} / \mathrm{dL}, p<.001)$. The primary efficacy parameter, percent atheroma volume (PAV), increased $0.05 \%$ with placebo and decreased $0.95 \%$ with EVO, $p<.001$ ). EVO induced plaque regression in more patients than placebo $(64.3 \%$ vs $47.3 \%, p<.001$ for PAV, and $61.5 \%$ vs $48.9 \%, p<.001$ for total atheroma volume (TAV)). The GLAGOV study also demonstrated a positive linear change in percent PAV as LDLC increased from $20 \mathrm{mg} / \mathrm{dl}$ to $110 \mathrm{mg} / \mathrm{dl}$.

Mendelian randomization studies suggest that a lifetime reduction of LDLC $\sim 40 \mathrm{mg} / \mathrm{dl}$ would reduce risk of ASCVD by $50 \%$ [42]. In our current study, the median LDLC reduction ranged from 67 to $104 \mathrm{mg} / \mathrm{dl}$, and 48 (67\%) of 72 patients achieved at least one LDLC on 
therapy $<70 \mathrm{mg} / \mathrm{dl}$. Moreover, according to the AHA and NIH 10-year CVD risk calculations, on ALI $75 \mathrm{mg}$ there was CVD risk reduction of 22 and 44\%, on ALI $150 \mathrm{mg}, 31$ and 50\%, and on EVO $140 \mathrm{mg}, 29$ and 56\%. The ACC/AHA calculator was not, however, designed for use in patients with pre-existing CVD events, although the NIH calculator has no such restriction [43]. In at least $50 \%$ of our patients on PCSK9 therapy with LDLC $<70 \mathrm{mg} / \mathrm{dl}$, from the past experience with vascular studies on statins [37, 38, 40] and recent GLAGOV study [38], we speculate that there should be significant regression of vascular plaque. Although not powered for CVD outcomes, the preliminary randomized controlled trials outcomes' data for ALI and EVO showed 50\% CVD event reduction [9-11]. Further hard CVD endpoint as well as vascular regression studies [41] are needed to assess for cardiovascular impact of the powerful LDLC reduction from PCSK9 therapy.

Assessment of potential adverse events is an important consideration when analyzing PCSK9 inhibitor use. In the current study, both ALI and EVO were generally welltolerated; the most significant frequent adverse event was flu-like myositis-myalgia in $10 \%$ of patients. There were however, no among-group differences between all three treatment groups for adverse events $(p>0.05)$. This is comparable to the pattern of side effects for ALI and EVO in randomized placebo-controlled trials [44, 45]. In a meta-analysis of 25 randomized controlled trials with PCSK9 inhibitors, there was no significant differences in major adverse event rates between the active drug and control treatment [46].

In the current study, of the 42 statin-intolerant patients, defined primarily as experiencing myalgias or myopathy on statins, $17 \%$ had mild to moderate flu-like myalgias. When comparing the statin-intolerant cohort on ALI or EVO versus those taking a statin plus ALI or EVO, there were fewer adverse events in the statin tolerant group than the statin intolerant group $(p=.04)$. Our results parallel those of the randomized, placebo-controlled GAUSS-3 study, where EVO was well-tolerated and effective in patients with statin intolerance [8]. Our conjecture is that the long-term adverse health consequences attributed to PCSK9 inhibitors may be minimal, particularly in statin tolerant patients.

In our real world, open label, post-commercialization evaluation of ALI and EVO, with $58 \%$ of patients being statin intolerant, and all having HeFH and/or CVD, our LDLC reduction was within $1-3 \%$ of the placebo-controlled trials for ALI $150 \mathrm{mg}$ and EVO $140 \mathrm{mg}$ groups, but the ALI $75 \mathrm{mg}$ group had 9\% higher LDLC lowering than earlier trials $[9,11]$. A second strength of our study was the finding that the adverse event profile on ALI or EVO was slightly lower in the statin tolerant patients taking both statins and ALI or EVO versus the statin intolerant patients taking only
ALI or EVO. Since 58\% of the cohort was intolerant to any statin at any dose regimen at entry, this emphasizes both the high frequency of statin intolerance in patients with high LDLC who fail to reach LDLC goals, and the efficacy of ALI and EVO inhibitors in stain intolerant patients. A third strength lies in the characterization of those patients who achieved LDLC $<70 \mathrm{mg} / \mathrm{dl}$ by each treatment group, and in the presence or absence of $\mathrm{HeFH}$ and/or CVD.

A limitation of this study is the relatively small group of patients. A second limitation is a probable bias towards higher risk patients with $\mathrm{HeFH}, \mathrm{CVD}$, and statin intolerance, unable to reach LDLC lowering goals on conventional LDLC-lowering therapy, by virtue of referral to a regional cholesterol treatment center.

\section{Conclusion}

In hypercholesterolemic patients with $\mathrm{HeFH}$, and/or CVD with suboptimal LDLC lowering on maximal tolerated cholesterol lowering therapy, LDLC was reduced by $63 \%$ on EVO $140 \mathrm{mg}$ and ALI $150 \mathrm{mg}$ and 54\% on ALI $75 \mathrm{mg}$ beyond the best antecedent cholesterol lowering program. Reported adverse events were minimal and tolerable. ALI and EVO represent paradigm shifts in LDLC lowering, and, speculatively, in reduction of CVD, with long-term safety and cardiovascular outcomes yet to be determined.

\section{Abbreviations \\ ACC: American college of cardiology; AHA: American heart association; ALI: Alirocumab; ASCVD: Atherosclerotic cardiovascular disease; \\ CVD: Cardiovascular disease; EVO: Evolocumab; HeFH: Heterozygous familial hypercholesterolemia; IVUS: Intravenous ultrasound; LDLC: Low-density lipoprotein cholesterol; NIH: National institute of health; PCSK9: Proprotein convertase subtilisin-kexin type 9; TIA: Transient ischemic attacks; WHO: World health organization}

\section{Acknowledgements}

Not applicable

\section{Funding}

Project funded in part by Lipoprotein Research Fund, The Jewish Hospital of Cincinnati.

Availability of data and material

Data can be found in our results section. If you have further data requests, please contact author

\section{Authors' Contributions}

PS and CJG contributed to study concept, study design, data gathering, data analysis, and editing and drafting of manuscript. NG contributed to study concept, data gathering, and data analysis. SM was involved in data gathering and editing of manuscript. CM, MR, and $\mathrm{AH}$ contributed to data gathering. IS contributed to data gathering and drafting of manuscript. PW was involved in data gathering, statistical data analysis, and editing of manuscript. All authors read and approved the final manuscript.

\section{Competing interests}

The authors declare that they have no competing interests.

Consent for publication

Not applicable. 


\section{Ethics approval and consent to participate}

The protocol was approved by Institutional Review Board of The Jewish Hospital and all ethical guidelines for human experimentation were followed. All study patients signed the informed consent after reviewing and understanding it thoroughly.

\section{Author details}

'Graduate Medical Education Department, Jewish Hospital of Cincinnati, Cincinnati, Ohio, USA. ${ }^{2}$ The Jewish Hospital Internal Medicine Residency Program, 4777 E Galbraith Rd, Cincinnati, Ohio 45236, USA.

Received: 14 October 2016 Accepted: 16 January 2017 Published online: 23 January 2017

\section{References}

1. Keenan NL, Shaw KM. Coronary heart disease and stroke deaths - United States, 2006. MMWR Suppl. 2011;60(1):62-6.

2. Mercado CDA, et al. Prevalence of cholesterol treatment eligibility and medication use among adults - united states, 2005-2012. MMWR Morb Mortal Wkly Rep. 2015;64(47):1305-11.

3. Kereiakes DJ, Robinson JG, Cannon CP, Lorenzato C, Pordy R, Chaudhari U, Colhoun HM. Efficacy and safety of the proprotein convertase subtilisin/ kexin type 9 inhibitor alirocumab among high cardiovascular risk patients on maximally tolerated statin therapy: the ODYSSEY COMBO I study. Am Heart J. 2015;169(6):906-915 e913.

4. Marks D, Thorogood M, Neil HA, Humphries SE. A review on the diagnosis, natural history, and treatment of familial hypercholesterolaemia. Atherosclerosis. 2003;168(1):1-14

5. Austin MA, Hutter CM, Zimmern RL, Humphries SE. Genetic causes of monogenic heterozygous familial hypercholesterolemia: a HuGE prevalence review. Am J Epidemiol. 2004;160(5):407-20.

6. Glueck CJ, Shah P, Goldenberg N, Prince M, Lee K, Jetty V, Kumar A, Goldenberg M, Wang P. Eligibility for PCSK9 treatment in 734 hypercholesterolemic patients referred to a regional cholesterol treatment center with $L D L$ cholesterol $>/=70 \mathrm{mg} / \mathrm{dl}$ despite maximal tolerated cholesterol lowering therapy. Lipids Health Dis. 2016;15(1):55.

7. Shah P, Glueck CJ, Jetty V, Goldenberg N, Rothschild M, Riaz R, Duhon G, Wang P. Pharmacoeconomics of PCSK9 inhibitors in 103 hypercholesterolemic patients referred for diagnosis and treatment to a cholesterol treatment center. Lipids Health Dis. 2016;15(1):132.

8. Nissen SE, Stroes E, Dent-Acosta RE, Rosenson RS, Lehman SJ, Sattar N, Preiss D, Bruckert E, Ceska R, Lepor N, et al. Efficacy and tolerability of evolocumab vs ezetimibe in patients with muscle-related statin intolerance: the GAUSS-3 randomized clinical trial. JAMA. 2016;315(15):1580-90.

9. Robinson JG, Farnier M, Krempf M, Bergeron J, Luc G, Averna M, Stroes ES, Langslet G, Raal FJ, El Shahawy M, et al. Efficacy and safety of alirocumab in reducing lipids and cardiovascular events. N Engl J Med. 2015;372(16):1489-99.

10. Robinson JG, Kastelein JJ. PCSK9 inhibitors and cardiovascular events. N Engl J Med. 2015;373(8):774.

11. Sabatine MS, Giugliano RP, Wiviott SD, Raal FJ, Blom DJ, Robinson J, Ballantyne CM, Somaratne R, Legg J, Wasserman SM, et al. Efficacy and safety of evolocumab in reducing lipids and cardiovascular events. N Engl J Med. 2015;372(16):1500-9.

12. Sabatine MS, Wasserman SM, Stein EA. PCSK9 inhibitors and cardiovascular events. N Engl J Med. 2015;373(8):774-5

13. Roth EM. Alirocumab for hyperlipidemia: ODYSSEY phase III clinical trial results and US FDA approval indications. Futur Cardiol. 2016;12(2):115-28.

14. Banach M, Rizzo M, Toth PP, Farnier M, Davidson MH, Al-Rasadi K, Aronow WS, Athyros V, Djuric DM, Ezhov MV, et al. Statin intolerance - an attempt at a unified definition. Position paper from an international lipid expert panel. Expert Opin Drug Saf. 2015;14(6):935-55.

15. Stroes ES, Thompson PD, Corsini A, Vladutiu GD, Raal FJ, Ray KK, Roden M, Stein E, Tokgozoglu L, Nordestgaard BG, et al. Statin-associated muscle symptoms: impact on statin therapy-european atherosclerosis society consensus panel statement on assessment. Aetiology and management. Eur Heart J. 2015;36(17):1012-22.

16. Grundy SM, Cleeman Jl, Merz CN, Brewer Jr HB, Clark LT, Hunninghake DB, Pasternak RC, Smith Jr SC, Stone NJ. Implications of recent clinical trials for the national cholesterol education program adult treatment panel III guidelines. J Am Coll Cardiol. 2004;44(3):720-32.
17. Jones PH, Nair R, Thakker KM. Prevalence of dyslipidemia and lipid goal attainment in statin-treated subjects from 3 data sources: a retrospective analysis. J Am Heart Assoc. 2012;1(6):e001800.

18. Stone NJ, Robinson JG, Lichtenstein AH, Bairey Merz CN, Blum CB, Eckel RH, Goldberg AC, Gordon D, Levy D, Lloyd-Jones DM, et al. 2013 ACC/AHA guideline on the treatment of blood cholesterol to reduce atherosclerotic cardiovascular risk in adults: a report of the american college of cardiology/ american heart association task force on practice guidelines. J Am Coll Cardiol. 2014;63(25 Pt B):2889-934.

19. Lloyd-Jones DM, Morris PB, Ballantyne CM, Birtcher KK, Daly Jr DD, DePalma SM, Minissian MB, Orringer CE, Smith Jr SC. 2016 ACC expert consensus decision pathway on the role of Non-statin therapies for LDL-cholesterol lowering in the management of atherosclerotic cardiovascular disease risk: a report of the american college of cardiology task force on clinical expert consensus documents. J Am Coll Cardiol. 2016;68(1):92-125.

20. Estimate of 10-Year Risk for Coronary Heart Disease Framingham Point Scores. https://www.nhlbi.nih.gov/health-pro/guidelines/current/cholesterolguidelines/quick-desk-reference-html/10-year-risk-framingham-table. Accessed 21 Jan 2017.

21. Weintraub WS, Gidding SS. PCSK9 inhibitors: a technology worth paying for? Pharmacoeconomics. 2016;34(3):217-20.

22. Neumann PJ, Cohen JT, Weinstein MC. Updating cost-effectiveness-the curious resilience of the $\$ 50,000-$ per-QALY threshold. N Engl J Med. 2014; 371(9):796-7.

23. Hsia SH, Desnoyers ML, Lee ML. Differences in cholesterol management among states in relation to health insurance and race/ethnicity across the United States. J Clin Lipidol. 2013;7(6):675-82.

24. Mann D, Reynolds K, Smith D, Muntner P. Trends in statin use and lowdensity lipoprotein cholesterol levels among US adults: impact of the 2001 national cholesterol education program guidelines. Ann Pharmacother. 2008;42(9):1208-15.

25. Waters DD, Brotons C, Chiang CW, Ferrieres J, Foody J, Jukema JW, Santos RD, Verdejo J, Messig M, McPherson R, et al. Lipid treatment assessment project 2: a multinational survey to evaluate the proportion of patients achieving lowdensity lipoprotein cholesterol goals. Circulation. 2009;120(1):28-34.

26. Glueck CJ, Budhani SB, Masineni SS, Abuchaibe C, Khan N, Wang P, Goldenberg N. Vitamin D deficiency, myositis-myalgia, and reversible statin intolerance. Curr Med Res Opin. 2011;27(9):1683-90.

27. Khayznikov M, Hemachrandra K, Pandit R, Kumar A, Wang P, Glueck CJ. Statin intolerance because of myalgia, myositis, myopathy, or myonecrosis Can in most cases be safely resolved by vitamin D supplementation. N Am J Med Sci. 2015;7(3):86-93.

28. Parker BA, Capizzi JA, Grimaldi AS, Clarkson PM, Cole SM, Keadle J, Chipkin S, Pescatello LS, Simpson K, White CM, et al. Effect of statins on skeletal muscle function. Circulation. 2013;127(1):96-103.

29. Wei MY, Ito MK, Cohen JD, Brinton EA, Jacobson TA. Predictors of statin adherence, switching, and discontinuation in the USAGE survey: understanding the use of statins in America and gaps in patient education. J Clin Lipidol. 2013; 7(5):472-83.

30. Everett BM, Smith RJ, Hiatt WR. Reducing LDL with PCSK9 inhibitors-the clinical benefit of lipid drugs. N Engl J Med. 2015;373(17):1588-91.

31. Shrank WH, Barlow JF, Brennan TA. New therapies in the treatment of high cholesterol: an argument to return to goal-based lipid guidelines. JAMA. 2015;314(14):1443-4

32. Stein EA, Raal FJ. Lipid-lowering drug therapy for CVD prevention: looking into the future. Curr Cardiol Rep. 2015;17(11):104.

33. Koren MJ, Scott R, Kim JB, Knusel B, Liu T, Lei L, Bolognese M, Wasserman SM. Efficacy, safety, and tolerability of a monoclonal antibody to proprotein convertase subtilisin/kexin type 9 as Monotherapy in patients with hypercholesterolaemia (MENDEL): a randomised, double-blind, placebocontrolled, phase 2 study. Lancet. 2012;380(9858):1995-2006.

34. McKenney JM, Koren MJ, Kereiakes DJ, Hanotin C, Ferrand AC, Stein EA. Safety and efficacy of a monoclonal antibody to proprotein convertase subtilisin/kexin type 9 serine protease, SAR236553/REGN727, in patients with primary hypercholesterolemia receiving ongoing stable atorvastatin therapy. J Am Coll Cardiol. 2012;59(25):2344-53.

35. Rallidis LS, Triantafyllis AS, Tsirebolos G, Katsaras D, Rallidi M, Moutsatsou P, Lekakis J. Prevalence of heterozygous familial hypercholesterolaemia and its impact on long-term prognosis in patients with very early ST-segment elevation myocardial infarction in the era of statins. Atherosclerosis. 2016; 249:17-21. 
36. Collins R, Reith C, Emberson J, Armitage J, Baigent C, Blackwell L, Blumenthal R, Danesh J, Smith GD, DeMets D, et al. Interpretation of the evidence for the efficacy and safety of statin therapy. Lancet. 2016; 388(10059):2532-61.

37. Kent SM, Coyle LC, Flaherty PJ, Markwood TT, Taylor AJ. Marked low-density lipoprotein cholesterol reduction below current national cholesterol education program targets provides the greatest reduction in carotid atherosclerosis. Clin Cardiol. 2004;27(1):17-21.

38. Taylor AJ, Kent SM, Flaherty PJ, Coyle LC, Markwood TT, Vernalis MN ARBITER: arterial biology for the investigation of the treatment effects of reducing cholesterol: a randomized trial comparing the effects of atorvastatin and pravastatin on carotid intima medial thickness. Circulation. 2002;106(16):2055-60.

39. Hunninghake DB. Is aggressive cholesterol control justified? review of the post-coronary artery bypass graft trial. Am J Cardiol. 1998;82(10B):45T-8T.

40. Nissen SE, Nicholls SJ, Sipahi I, Libby P, Raichlen JS, Ballantyne CM, Davignon J, Erbel R, Fruchart JC, Tardif JC, et al. Effect of very high-intensity statin therapy on regression of coronary atherosclerosis: the ASTEROID trial. JAMA. 2006;295(13):1556-65.

41. Nicholls SJ, Puri R, Anderson T, Ballantyne CM, Cho L, Kastelein JJ, Koenig W, Somaratne R, Kassahun H, Yang J, et al. Effect of Evolocumab on Progression of Coronary Disease in Statin-Treated Patients: The GLAGOV Randomized Clinical Trial. JAMA 2016;316(22):2373-84.

42. Ference BA, Yoo W, Alesh I, Mahajan N, Mirowska KK, Mewada A, Kahn J, Afonso L, Williams Sr KA, Flack JM. Effect of long-term exposure to lower low-density lipoprotein cholesterol beginning early in life on the risk of coronary heart disease: a Mendelian randomization analysis. J Am Coll Cardiol. 2012;60(25):2631-9.

43. D'Agostino Sr RB, Grundy S, Sullivan LM, Wilson P, Group CHDRP. Validation of the Framingham coronary heart disease prediction scores: results of a multiple ethnic groups investigation. JAMA. 2001;286(2):180-7.

44. Amgen: Highlights of Prescribing Information Repatha. In. Thousand Oaks, California; 2015

45. Sanofi/Regeneron: Highlights of Prescribing Information Praluent. In.; 2015.

46. Zhang XL, Zhu QQ, Zhu L, Chen JZ, Chen QH, Li GN, Xie J, Kang LN, Xu B. Safety and efficacy of anti-PCSK9 antibodies: a meta-analysis of 25 randomized, controlled trials. BMC Med. 2015;13:123.

\section{Submit your next manuscript to BioMed Central and we will help you at every step:}

- We accept pre-submission inquiries

- Our selector tool helps you to find the most relevant journal

- We provide round the clock customer support

- Convenient online submission

- Thorough peer review

- Inclusion in PubMed and all major indexing services

- Maximum visibility for your research

Submit your manuscript at www.biomedcentral.com/submit

) Biomed Central 